\title{
Dose-dependent effect of Curcuma longa for the treatment of Parkinson's disease
}

\author{
XIAO-WEI MA and RUI-YOU GUO \\ Department of Neurology, Haici Hospital Affiliated to Medical College of Qingdao University, \\ Qingdao, Shandong 266000, P.R. China
}

Received June 3, 2015; Accepted July 22, 2016

DOI: $10.3892 /$ etm.2017.4225

\begin{abstract}
Curcuma longa is a plant that belongs to the ginger family, Zingiberaceae. It has been used in Siddha medicine for thousands of years in Asia. Parkinson's disease (PD) is a degenerative disorder of the central nervous system that affects the motor system of the brain. Death of dopamine-producing cells in the substantia nigra leads to PD. Exposure to salsolinol, which is an endogenous neurotoxin, has been associated with damage to dopamine-producing cells. The present study assessed the toxicity of salsolinol in SH-SY5Y human neuroblastoma cells and subsequently investigated the neuroprotective potential of $C$. longa extract in salsolinol-induced toxic conditions in SH-SY5Y cells. Sulphorhodamine-B assay showed the protective effect of the anti-apoptotic effect of treated SH-SY5Y cells. Fluorescence microscopy and confocal laser scanning microscope analysis indicated the anti-apoptotic impact of the $C$. longa extract. Mitochondria-derived reactive oxygen species were reduced in $C$. longa extract-treated SH-SY5Y cells. Downregulated mRNA expression levels of p53, $\mathrm{Bcl}-2$-associated $\mathrm{X}$ protein and caspase 3 were observed in the $C$. long $a$ extract-treated SH-SY5Y cells. Caspase 3 activity was reduced in the $C$. longa extract-treated SH-SY5Y cells. In conclusion, the present findings demonstrated that solsolinol is neurotoxic to $\mathrm{SH}-\mathrm{SY} 5 \mathrm{Y}$ cells, and $C$. longa extract may be useful in the treatment of PD.
\end{abstract}

\section{Introduction}

Curcuma longa (turmeric) is a rhizomatous herbaceous perennial plant of the ginger family, Zingiberaceae. It is also known as kasturi manjal, and has been used in Siddha medicine for more than a thousand years in Asia (1) as a

Correspondence to: Professor Xiao-Wei Ma, Department of Neurology, Haici Hospital Affiliated to Medical College of Qingdao University, 4 Renming Road, Qingdao, Shandong 266000, P.R. China

E-mail: maxiaowei76@hotmail.com

Key words: Parkinson's disease, Curcuma longa, SH-SY5Y cells, caspase 3 , solsolinol medicine for various ailments, including skin diseases, pulmonary issues, aches, pains, wounds, sprains and gastrointestinal system issues (2). Furthermore, it has been used to treat stomach and liver diseases, and it contains a high antimicrobial potential (3). The active component of $C$. longa extract is a curcuminoid (4). C. longa extract is known to have anti-inflammatory $(5,6)$, antioxidant $(7)$ and anti-depressant potential (8-11). Previous studies have reported that $C$. longa extract is very effective against inflammation and Alzheimer's disease $(12,13)$.

Parkinson's disease (PD) is a neurodegenerative disorder characterized by damage to the dopamine-producing cells in the substantia nigra of the brain. Environment factors and genetic predisposition have a crucial role in the progression of PD. Tieu (14) has previously reported that exposure to several endogenous and exogenous toxins has been associated with PD. Therefore, these endogenous and exogenous toxins are often used to study PD. The endogenous toxin, salsolinol is a neuromodulator of dopamine-producing cells in the substantia nigra (15). Dysregulation of salsolinol metabolism is known to contribute to the progressive development of PD (16). Increased levels of salsolinol and its derivatives in the cerebrospinal fluid and urine may serve as an index for the PD $(17,18)$.

Previous studies have reported that the extract of $C$. longa may be useful in the treatment of PD $(19,20)$. Therefore, the present study investigated this effect. The toxicity of salsolinol was investigated in SH-SY5Y cells derived from human neuroblastoma cells $(21,22)$, in order to investigate the therapeutic potential of $C$. longa extract.

\section{Materials and methods}

Materials. SH-SY5Y human neuroblastoma cells were purchased from American Type Culture Collection (Manassas, VA, USA). Dimethyl sulphoxide and sulforhodamine B (SRB), Dulbecco's modified Eagle's medium (DMEM), fetal bovine serum (FBS), penicillin-streptomycin and trypsin-EDTA were obtained from were obtained from Sigma-Aldrich (Merck Millipore, Darmstadt, Germany). Acridine orange (AO), ethidium bromide (EB) Fluorescein diacetate, propidium iodide (PI) and 2,7-dichlorodihydrofluorescein diacetate (DCFH-DA) were purchased from Santa Cruz Biotechnology, Inc., (Dallas, TX, USA). 
Cell culture. SH-SY5Y human neuroblastoma cells (sixth passage) were cultured in DMEM supplemented with $10 \%$ FBS and $1 \%$ penicillin-streptomycin. Cells were grown in a $\mathrm{CO}_{2}$ incubator at $37^{\circ} \mathrm{C}$ and $5 \% \mathrm{CO}_{2}$. The protocol for the present study was approved by the Ethics Committee of the Affiliated Hospital of Qingdao University.

Preparation of C. longa extracts. Water extraction of C. longa extract was performed by boiling $100 \mathrm{~g}$ in $1,000 \mathrm{ml}$ distilled water for 15 min over a low flame. The flask was subsequently plugged, removed from the heat and allowed to cool. The extract was filtered and dried to prepare the required concentrations after cooling the content of the flask.

C. longa extract pre-treatment. Various concentrations of C. longa extract $(0.001,0.01,0.05,0.1,0.2$ and $0.4 \mathrm{mg} / \mathrm{ml})$ were added $1 \mathrm{~h}$ prior to the addition of salsolinol to investigate its therapeutic potential against PD. SRB assay was used to assess cell viability after 24 and $48 \mathrm{~h}$ of treatment.

Salsolinol treatment. Once the SH-SY5Y cells reached 90\% confluence, the cells were plated in 96-well plate and allowed to adhere for $24 \mathrm{~h}$. Various concentrations of salsolinol ( 0.001 , $0.01,0.05,0.1,0.5$ and $1 \mathrm{mg} / \mathrm{ml}$ ) were added to the cells ( $2 \times 10^{4}$ cells/well). SRB assay was used to assess cell viability after 24 and $48 \mathrm{~h}$ of treatment.

SRB assay for cell viability. SH-SY5Y cells were cultured and grown at a density of $2.5 \times 10^{4}$ cells/well in 96 -well plates. Cells were treated with $C$. longa extract and salsolinol at various concentrations for 24 and $48 \mathrm{~h}$. The cytotoxic effect of salsolinol and therapeutic potential of $C$. longa extract on SH-SY5Y cells were measured by the SRB assay, which was performed as previously described (23).

Fluorescence microscopy. Cells were cultured and grown at a density of $2.2 \times 10^{4}$ cells/well into 6 -well plates. SH-SY5Y cells were treated with $0.05 \mathrm{mg} / \mathrm{ml}$ salsolinol, $1 \mathrm{~h}$ prior to the addition of $C$. longa extract $(0.05$ and $0.1 \mathrm{mg} / \mathrm{ml})$. After 24 and $48 \mathrm{~h}$, cells were removed from the wells and centrifuged at $500 \mathrm{x} \mathrm{g}$ for $3 \mathrm{~min}$. The supernatant was withdrawn from the tubes and phosphate-buffered saline (PBS) was added to the cells. Cell volume was adjusted to $10^{5}-10^{6}$ cells $/ \mathrm{ml}$. A total of $95 \mu \mathrm{l}$ cell suspension was added to the microtube, and $5 \mu \mathrm{l} \mathrm{AO}$ and EB was added to the same tube. Cells were incubated at $37^{\circ} \mathrm{C}$ for $15-30 \mathrm{~min}$ in the dark. Subsequently, $10 \mu \mathrm{l}$ cell staining solution was added to a glass slide and covered with a cover glass. Cells were examined with a fluorescence microscope (Axiovert 2000; Carl Zeiss AG, Oberkochen, Germany) (24).

Confocal laser scanning microscope analysis (CLSM). CLSM is widely used to investigate morphological features of apoptosis and apoptotic DNA fragmentation (24). AO is an organic compound that is extensively used as a nucleic acid-selective fluorescent cationic dye for the determination of the cell cycle (24). AO interacts with DNA and RNA by intercalation or electrostatic attractions respectively, and spectrally fluorescein when bound to DNA with an excitation maximum at $502 \mathrm{~nm}$, and an emission maximum at $525 \mathrm{~nm}$ (24). SH-SY5Y cells $\left(2 \times 10^{4}\right.$ cells/well) were seeded in a confocal dish and subsequently treated with $0.05 \mathrm{mg} / \mathrm{ml}$ salsolinol $1 \mathrm{~h}$ prior to the addition of $C$. longa extracts $(0.05$ and $0.1 \mathrm{mg} / \mathrm{ml})$. After 24 and $48 \mathrm{~h}$, cells were washed thrice with PBS and stained with $\mathrm{AO}(20 \mu \mathrm{g} / \mathrm{ml})$ for $5 \mathrm{~min}$. Cells were immediately viewed under a CLSM (1X81R motorized inverted microscope; Olympus Corp., Tokyo, Japan) (24).

Determination of reactive oxygen species (ROS) production. ROS was determined using a fluorescent probe, DCFH-DA (25). SH-SY5Y cells were seeded in 96-well plates in growth medium at a density of 4,000 cells/well under standard conditions. Cells were treated with $0.05 \mathrm{mg} / \mathrm{ml} \mathrm{salso-}$ linol, $1 \mathrm{~h}$ prior to the addition of C. longa extract ( 0.05 and $0.1 \mathrm{mg} / \mathrm{ml})$. After 24 and $48 \mathrm{~h}$, the medium was removed, and the cells were incubated with $5 \mu \mathrm{M}$ DCFH-DA in the growth medium for $30 \mathrm{~min}$ at $37^{\circ} \mathrm{C}$ and $5 \% \mathrm{CO}_{2}$. Fluorescence was measured at 24 and $48 \mathrm{~h}$ using a fluorescent plate reader at excitation/emission (490 and $525 \mathrm{~nm}$ respectively). Images were captured using a fluorescence microscope.

Reverse transcription-quantitative polymerase chain reaction $(R T-q P C R)$. SH-SY5Y cells $\left(2 \times 10^{4}\right.$ cells/well $)$ were seeded into a T25 flask and subsequently treated with $0.05 \mathrm{mg} / \mathrm{ml}$ salsolinol, $1 \mathrm{~h}$ prior to the addition of $C$. longa extract $(0.05$ and $0.1 \mathrm{mg} / \mathrm{ml})$. After 24 and $48 \mathrm{~h}, 100 \mathrm{ng}$ total RNA was isolated from the control and treated samples (26). RNA was reverse transcribed using Taq DNA polymerase (D1806; Sigma-Aldrich; Merck Millipore) with a total reaction volume of $25 \mu \mathrm{l}$. Following treatment with DNase (AMPD1; Sigma-Aldrich; Merck Millipore), qPCR was performed using cDNA equivalent to $10 \mathrm{ng}$ total RNA from each sample in a total reaction volume of $10 \mu l$, containing SYBR Green (A25741; Thermo Fisher Scientific, Inc.), $12.5 \mu \mathrm{l}$ PCR Master Mix (2X), 0.25-2.5 $\mu 1$ upstream primer $(10 \mu \mathrm{M}), 0.25-2.5 \mu \mathrm{l}$ downstream primer $(10 \mu \mathrm{M}), 1-5 \mu \mathrm{l}$ DNA template and nuclease-free water. Primers were specific for p53 (forward, 5'-TAACAGTTCCTGCATGGGCGGC-3' and reverse, 5'-AGGACAGGCACAAACACGCACC-3'), Bcl-2-associated $\mathrm{X}$ protein (Bax) (forward, 5'-TGGAGC TGCAGAGGATGATTG-3' and reverse, 5'-GAAGTTGCC GTCAGAAAACATG-3'), caspase 3 (forward, 5'-TTAATA AAGGTATCCATGGAGAACACT-3' and reverse, 5'-TTA GTGATA AAA ATAGAGTTC TTTTGTGAG-3') and a housekeeping gene GAPDH (forward, 5'-GGTCACCAG GGCTGCTTTT-3' and reverse, 5'-ATCTCGCTCCTGGAA GATGGT-3'). Thermal cycling conditions were as follows and were performed on an Applied Biosystems PCR thermal cycler (Applied Biosystems; Thermo Fisher Scientific, Inc.): Annealing at $50-68^{\circ} \mathrm{C}$ for $1 \mathrm{~min}$, followed by 40 cycles at $68^{\circ} \mathrm{C}$ for $1 \mathrm{~min}$. Relative ratios were calculated based on the $2^{-\Delta \Delta C q}$ method (27). PCR was monitored using the CFX96TM Real-Time System (Bio-Rad Laboratories, Inc., Hercules, CA, USA). A total of 25 repeats were performed and GAPDH was used as the reference gene.

Caspase 3 activity assay. SH-SY5Y cells $\left(2 \times 10^{4}\right.$ cells/well) were seeded in the culture dish and subsequently treated with $0.05 \mathrm{mg} / \mathrm{ml}$ of salsolinol, $1 \mathrm{~h}$ before the addition of C. longa extract $(0.05$ and $0.1 \mathrm{mg} / \mathrm{ml})$. After 24 and $48 \mathrm{~h}$, caspase 3 


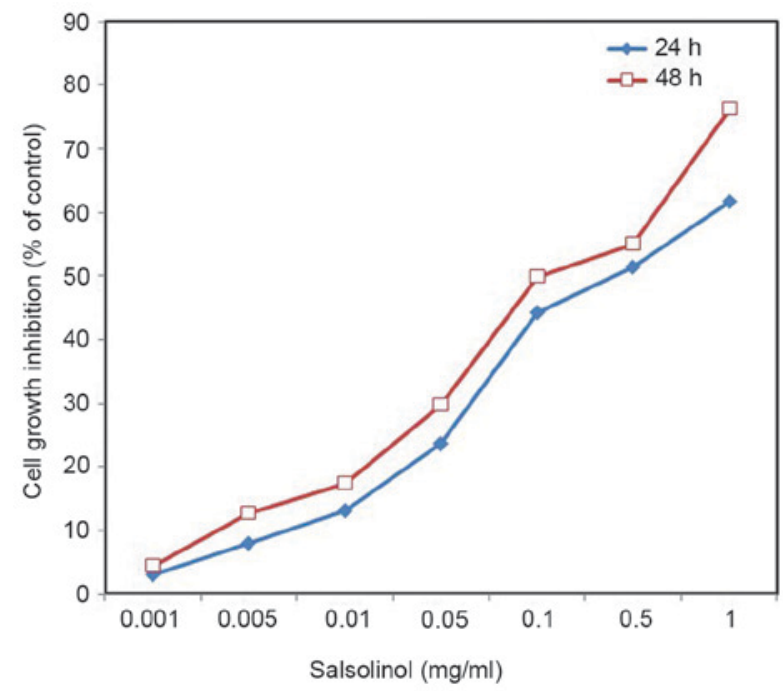

Figure 1. Cytotoxic effect of salsolinol in SH-SY5Y cells, as assessed by sulforhodamine B assay at 24 and $48 \mathrm{~h}$. Results are presented as a percentage of growth inhibition compared with the control. Percentage of growth inhibition was calculated as follows: Growth inhibition $(\%)=($ control - sample $/$ control $) \times 100$. Values are expressed as means \pm standard error of the mean.

enzyme activity was measured based on the method outlined by Muthuraman (28).

Statistical analysis. Data were expressed as the mean \pm standard error of the mean. Differences between control and treated cells were evaluated using Student's t-test. $\mathrm{P}<0.05$ was considered to indicate a statistically significant difference.

\section{Results}

Effect of salsolinol on cell viability. Salsolinol induced a neurotoxic effect on SH-SY5Y cells in a dose-dependent manner (Fig. 1). As $1 \mathrm{mg} / \mathrm{l}$ salsolinol was able to significantly inhibit the growth of SH-SY5Y cells, $0.05 \mathrm{mg} / 1$ salsolinol was used for subsequent experiments. An inverted microscope was used to observe cell shape and morphological changes. Control SH-SY5Y cells exhibited normal distinct morphology, whereas salsolinol-treated cells exhibited sporadic distribution, loss of adhesion and a rounding/oval profile (data not shown).

Effect of C. longa extract on cell viability. C. longa extract had a dose-dependent therapeutic effect on the viability of SH-SY5Y cells (Fig. 2). As $1 \mathrm{mg} / \mathrm{l} \mathrm{C}$. longa extract induced an adverse effect on normal cells, 0.05 and $0.1 \mathrm{mg} / \mathrm{l} C$. longa extract was used for subsequent experiments. An inverted microscope was used to observe cell shape and morphological changes. Control cells exhibited irregular morphology, such as rounding and a reduction in nuclear volume. $C$. longa extract-treated cells demonstrated a significant reduction in cell growth inhibition $(\mathrm{P}<0.05$; Fig. 2$)$.

Effect of $C$. longa extract on apoptosis. Fluorescence microscopy was performed to determine whether the neuroprotective impact of $C$. longa extract was associated

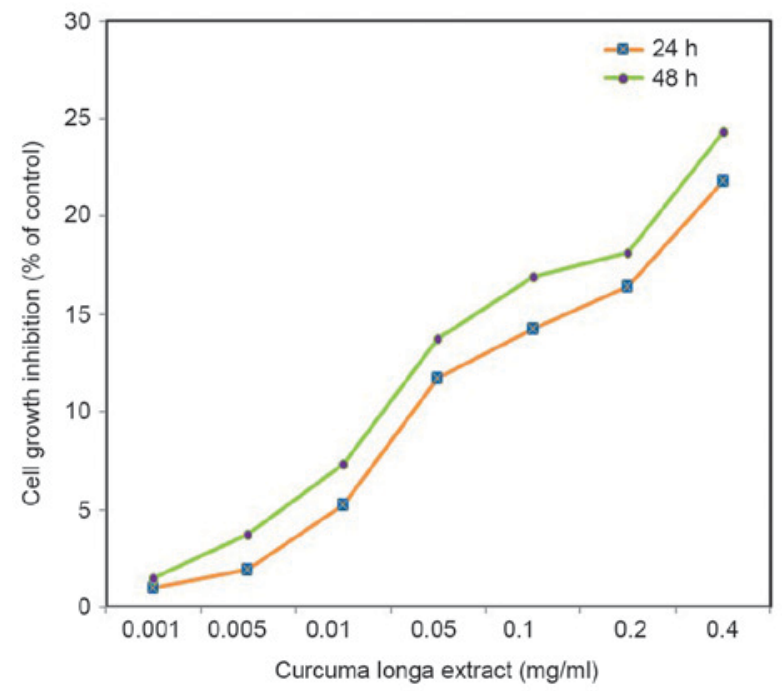

Figure 2. Cytotoxic effect of the Curcuma longa extract in salsolinol induced SH-SY5Y cells, as assessed by sulforhodamine B assay at 24 and $48 \mathrm{~h}$. Results are presented as a percentage of growth inhibition compared with the control. Percentage of growth inhibition was calculated as follows: Growth inhibition $(\%)=($ control - sample / control $) \times 100$. Values are expressed as means \pm standard error of the mean.

with the induction of apoptosis, by assessing the morphological features of cell death. This method combines the dual uptake of fluorescent DNA binding dyes (AO and EB), and chromatin condensation in the stained nucleus can be used to differentiate between viable, apoptotic, and necrotic cells (24). Control cells exhibited irregular morphological features, such as rounding and a reduction in nuclear volume, whereas $C$. longa extract-treated cells demonstrated normal morphological features (Figs. 3 and 4).

CLSM was used to investigate the morphological features of apoptosis and apoptotic DNA fragmentation in the SH-SY5Y cells. Control cells exhibited irregular morphological features, such as rounding and a reduction in nuclear volume, as compared with treated cells. Morphological changes included rounding, compact granular masses in the nucleus and reduced nuclear volume in the treated cells. A bright green nucleus indicated the induction of apoptosis in the treated cells (Figs. 5 and 6).

Effect of $C$. longa extract on ROS level. ROS have an essential role in facilitating signal transduction processes within the intracellular region. Intracellular ROS generation was determined using a DCFH-DA fluorescent probe. Fluorescence analysis indicated that the green fluorescence intensity of DCF was significantly reduced in the treated cells, as compared with the control cells (Fig. 7; P<0.05). Furthermore, fluorescence analysis indicated the apparent action of $C$. longa extract on intracellular ROS generation in a dose-dependent manner (Fig. 7).

Effect of C. longa extract on gene expression levels. To further assess the impact of $C$. longa extract on apoptosis, RT-qPCR analysis was performed in the present study to quantify the expression levels of apoptotic markers. Cells exposed to various concentrations of the $C$. longa extract exhibited 

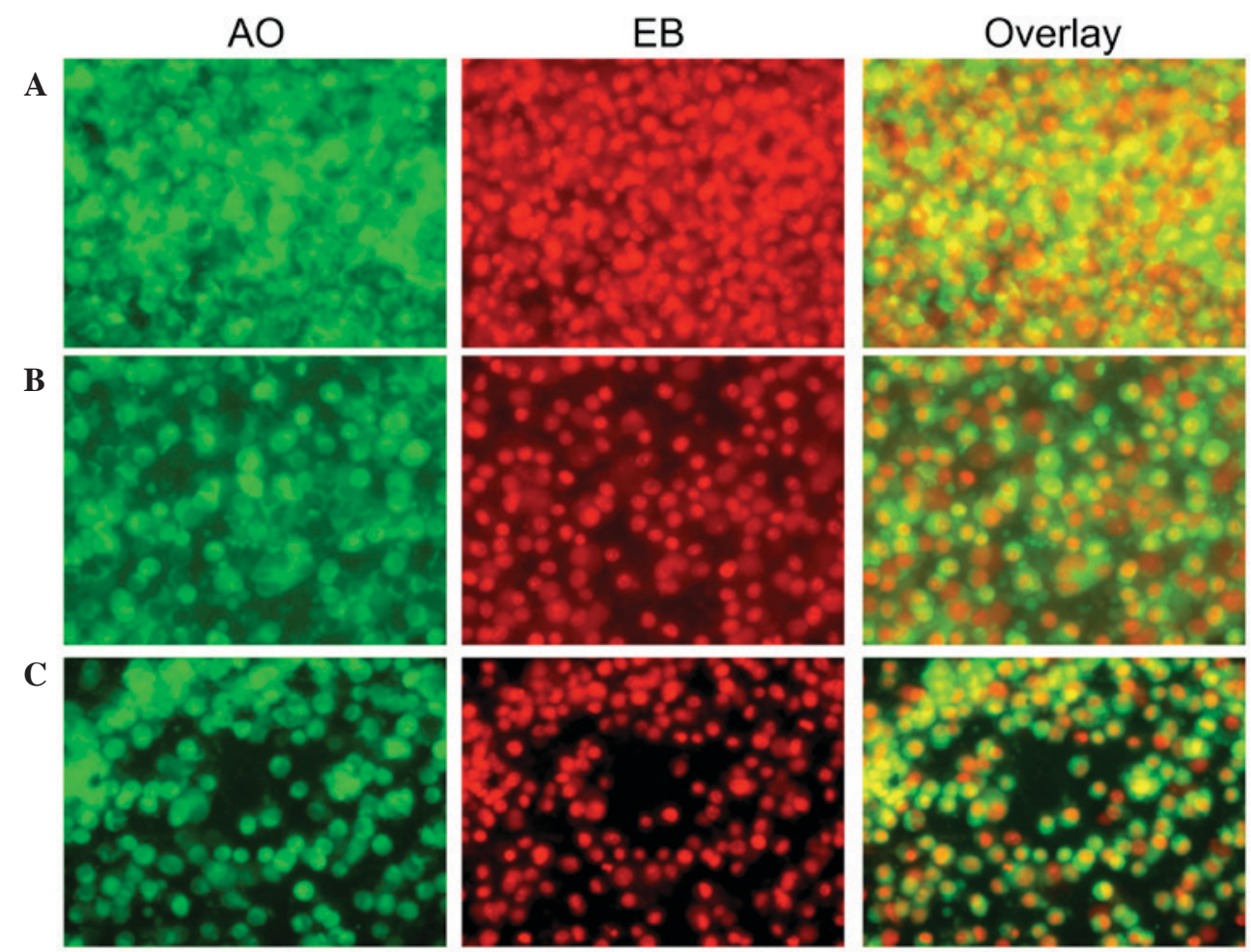

Figure 3. Morphological observation with AO/EB double staining by fluorescence microscopy (magnification, x40). SH-SY5Y cells were seeded in 6-well plates and following 24-h adherence, were treated with (A) 0 , (B) 0.5 and (C) $0.1 \mathrm{mg} / \mathrm{ml}$ Curcuma longa extract for $24 \mathrm{~h}$. Following treatment, $95 \mu 1$ cell suspension was mixed with $5 \mu \mathrm{l}$ dye mixture, containing $100 \mathrm{mg} / \mathrm{l}$ of AO and $100 \mathrm{mg} / \mathrm{l}$ of EB in phsophate-buffered saline. Subsequently, stained cells were visualized immediately under a fluorescence microscope. Viable cells were detected in the controls. Fragmented nuclei, condensed chromatin, and apoptotic cells were detected in the $C$. longa extract-treated cells. Representative images from three independent experiments. AO, acridine orange; EB, ethidium bromide.
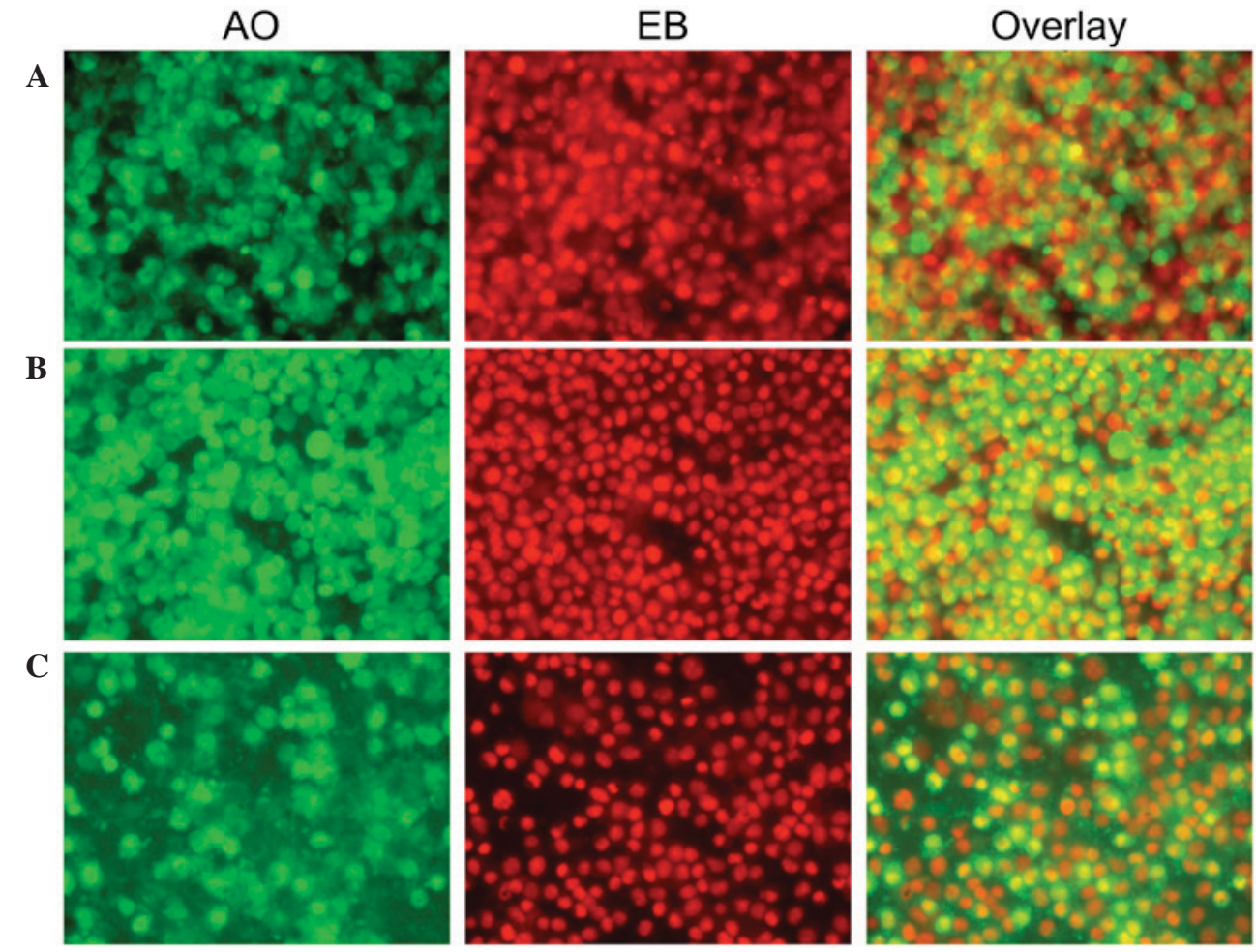

Figure 4. Morphological observation with AO/EB double staining by fluorescence microscopy (magnification, x40). SH-SY5Y cells were seeded in 6-well plates and, following 48-h adherence, were treated with (A) 0 , (B) 0.5 and (C) $0.1 \mathrm{mg} / \mathrm{ml}$ Curcuma longa extract for $48 \mathrm{~h}$. Following treatment, $95 \mu 1$ cell suspension was mixed with $5 \mu \mathrm{l}$ dye mixture, containing $100 \mathrm{mg} / 1$ of AO and $100 \mathrm{mg} / \mathrm{l}$ of EB in phsophate-buffered saline. Subsequently, stained cells were visualized immediately under a fluorescence microscope. Viable cells were detected in the controls. Fragmented nuclei, condensed chromatin, and apoptotic cells were detected in the $C$. longa extract-treated cells. Representative images from three independent experiments. AO, acridine orange; EB, ethidium bromide. 


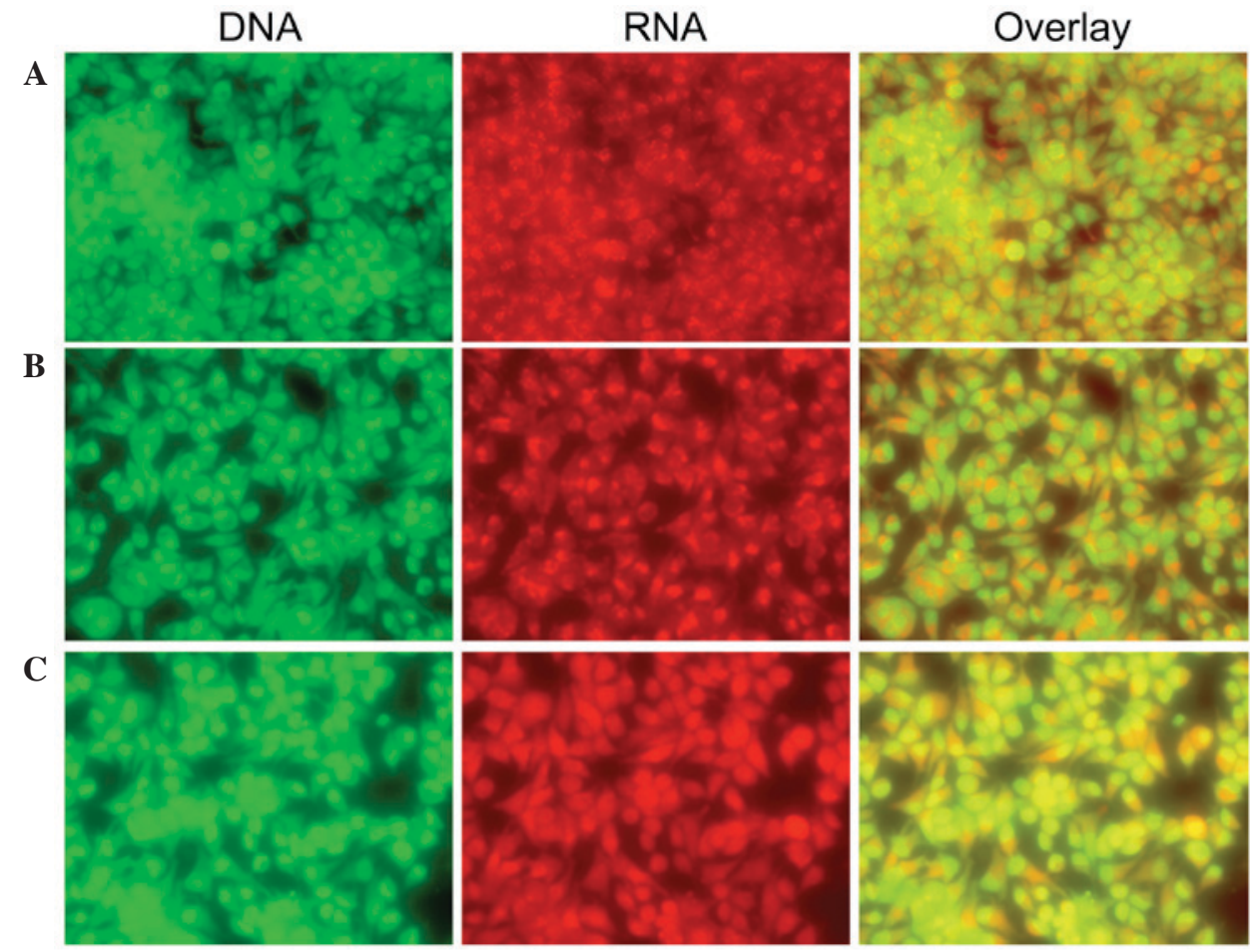

Figure 5. Morphological observation of SH-SY5Y cells by CLSM (magnification, $\mathrm{x} 40$ ). Cells were grown on the cover glass confocal dish. Cells were treated with the (A) 0 , (B) 0.5 and (C) $0.1 \mathrm{mg} / \mathrm{ml}$ Curcuma longa extract for $24 \mathrm{~h}$. At the end of $24 \mathrm{~h}$, cells were stained with $20 \mu \mathrm{g} / \mathrm{ml} \mathrm{AO}$ dye for 5 min and washed twice with phosphate-buffered saline, and were immediately viewed under CLSM. Green indicates DNA, red indicates RNA and the overlay images represent the merging of the DNA and RNA fluorescence images. Representative images from three independent experiments. CLSM, confocal laser scanning microscope analysis.

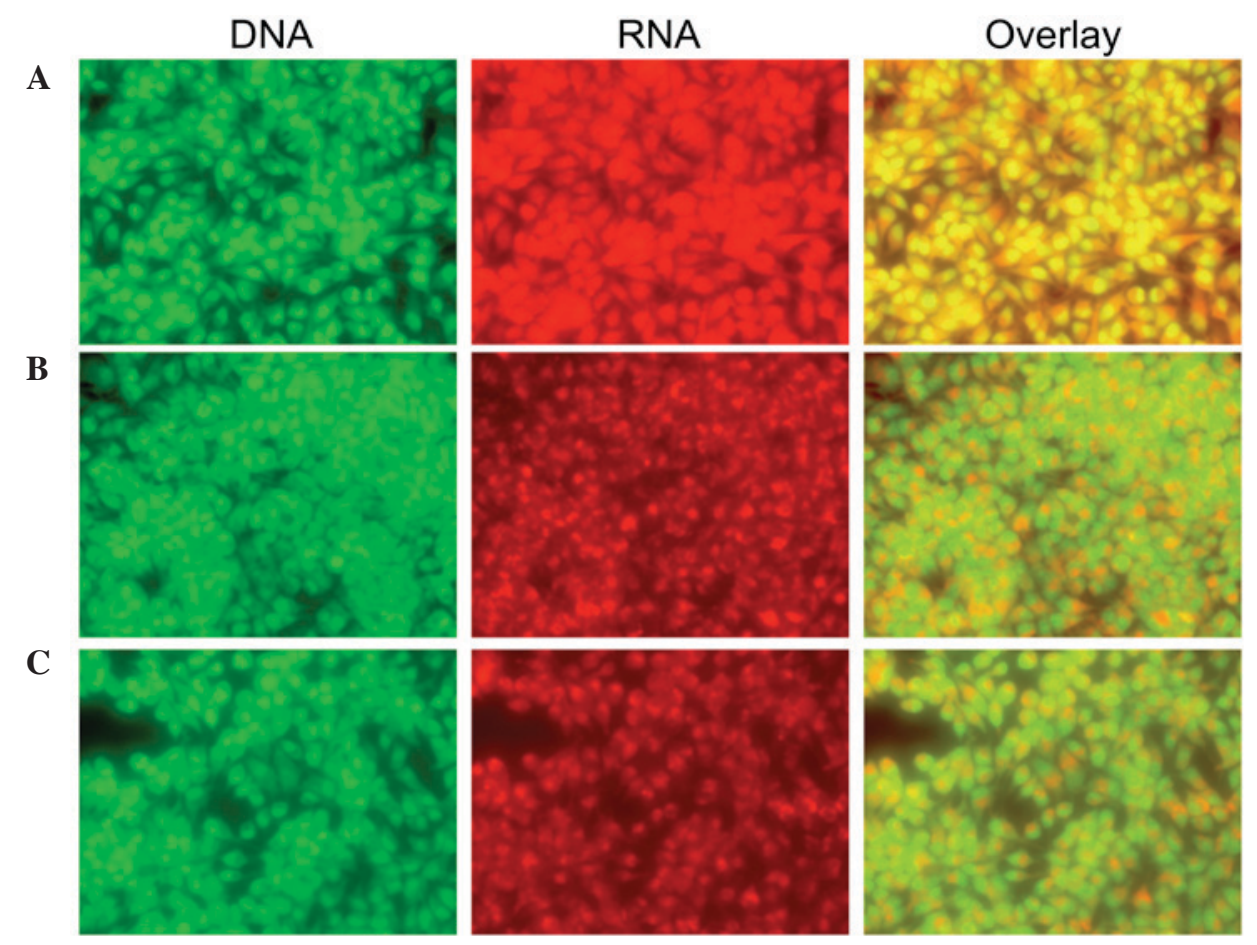

Figure 6. Morphological observation of SH-SY5Y cells by CLSM (magnification, $\mathrm{x} 40$ ). Cells were grown on the cover glass confocal dish. Cells were treated with the (A) 0 , (B) 0.5 and (C) $0.1 \mathrm{mg} / \mathrm{ml}$ Curcuma longa extract for $48 \mathrm{~h}$. At the end of $48 \mathrm{~h}$, the cells were stained with $20 \mu \mathrm{g} / \mathrm{ml} \mathrm{AO}$ dye for $5 \mathrm{~min}$ and washed twice with phosphate-buffered saline, and were immediately viewed under CLSM. Green indicates DNA, red indicates RNA and the overlay images represent the merging of the DNA and RNA fluorescence images. CLSM, confocal laser scanning microscope analysis.

significantly downregulated mRNA expression levels of $\mathrm{p} 53$, Bax and caspase 3 in a time- and concentration-dependent manner (Fig. 8; $\mathrm{P}<0.05$ ).
Effect of $C$. longa extract on caspase 3 activity. To further examine the participation of caspase 3 in the effect induced by C. longa extract on apoptosis, caspase 3 activity was measured 


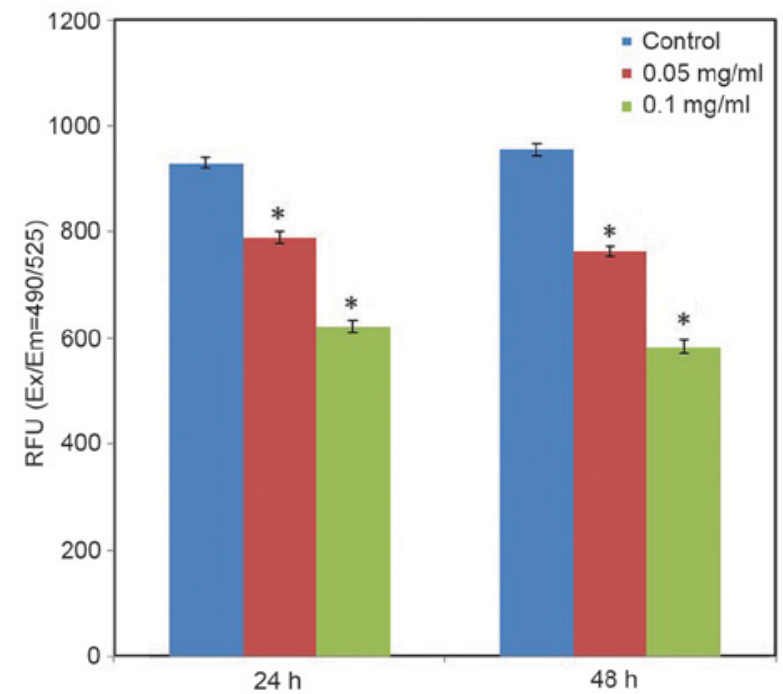

Figure 7. Alterations in fluorescence intensity. SH-SY5Y cells were grown in 6-well plates and allowed to adhere for $24 \mathrm{~h}$. Cells were treated with Curcuma longa extract ( 0.05 and $0.1 \mathrm{mg} / \mathrm{ml})$ for 24 and $48 \mathrm{~h}$, respectively. Cells were stained with dye and images were captured via fluorescence microscopy. " $\mathrm{P}<0.05$ vs. control. RFU, relative fluorescent units; Ex, excitation; Em, emission.

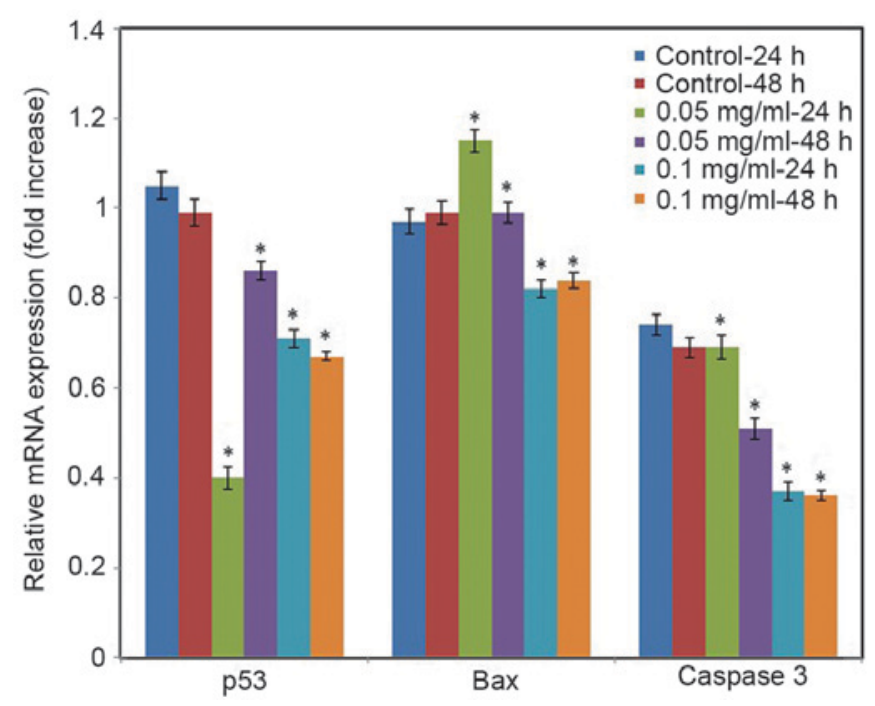

Figure 8. mRNA expression levels of apoptotic markers (p53, bax and caspase 3) were assessed by reverse transcription-quantitative polymerase chain reaction (RT-qPCR). SH-SY5Y cells were grown in a T-25 flask and allowed to adhere for $24 \mathrm{~h}$. Cells were treated with the Curcuma longa extract ( 0.05 and $0.1 \mathrm{mg} / \mathrm{ml}$ ) for 24 and $48 \mathrm{~h}$. Following treatment, RNA was isolated from the cells and RT-qPCR was performed. Values are expressed as means \pm standard error of the mean. ${ }^{*} \mathrm{P}<0.05$ vs. control. Bax, Bcl-2 associated $\mathrm{X}$ protein.

at the translational level. Caspase 3 activity significantly was reduced in the C. longa extract-treated SH-SY5Y cells (Fig. 9; $\mathrm{P}<0.05)$.

\section{Discussion}

The results of the present study demonstrated that $C$. longa extract has a neuroprotective effect in SH-SY5Y cells and seemed to exhibit a clear dose-dependence when used in higher concentrations. Induction of tumor cell apoptosis

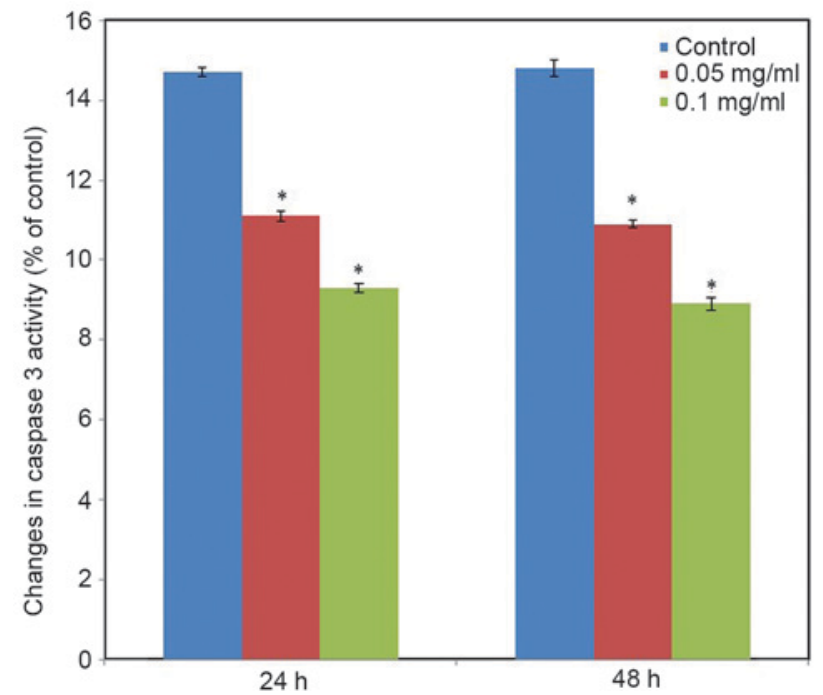

Figure 9. Alterations in caspase 3 activity. SH-SY5Y cells were grown in a T-75 flask and allowed to adhere for $24 \mathrm{~h}$. Cells were treated with Curcuma longa extract $(0.05$ and $0.1 \mathrm{mg} / \mathrm{ml})$ for 24 and $48 \mathrm{~h}$, respectively. Following treatment, cells were removed, and activity was determined based on the method outlined by Muthuraman (28). Values are expressed as means \pm standard error of the mean. ${ }^{*} \mathrm{P}<0.05$ vs. control.

is an essential mechanism of anti-cancer compounds (29). Apoptosis is characterized by morphological and biochemical changes and, the apoptosis of different cells in the same tissue does not occur at the same time. Morphological observation is critical for the assessment of apoptosis in the early stage as DNA multiples may be observed after the initiation of apoptosis. In the present study, C. longa extract exerted a therapeutic effect on SH-SY5Y cells at various concentrations. Morphological observation was performed to investigate whether the cytotoxic impact of the $C$. longa extract was correlated with the apoptotic process.

The findings showed that salsolinol is able to induce neurotoxicity in SH-SY5Y cells $(30,31)$, and the effect of treatment with $C$. longa extract suggested a therapeutic potential in the PD. Treatment with a low concentration of C. longa extract was able to significantly protect against the neurotoxicity induced by salsolinol in the SH-SY5Y cells. Salsolinol has been demonstrated to induce neurotoxicity via the inhibition of mitochondrial complex II, and the initiation of apoptosis through the increased production of free radicals (32). Salsolinol may contribute the pathogenesis of PD through the formation of inflammation as the neurotoxicity induced by salsolinol is mediated through apoptosis, and is caspase 3 dependent (33).

C. longa extract is known to induce neuroprotective effects through the inhibition of apoptosis with a consequent reduction in the gene expression levels of apoptotic markers, including p53, Bax and caspase 3. Even when administered at high concentrations, the $C$. longa extract was able to partially recover/inhibit the toxicity induced by salsolinol in SH-SY5Y cells. However, the effect of $C$. longa extract was demonstrated to be significant. Subsequent investigation of C. longa extract in combination with other agents is required to elucidate their potentially synergistic actions (34), and it would be helpful to determine the therapeutic effect of 
C. longa extract as a monotherapy and in combination with other agents.

Antioxidant and anti-inflammatory properties of the C. longa extract would be helpful in the treatment of PD (5). There are several studies suggesting a significant co-morbidity between depression and PD (35). The mood regulating potential of the $C$. longa extract would be additionally helpful it treating PD (11).

In conclusion, salsolinol was demonstrated to be cytotoxic to SH-SY5Y cells when observed by SRB assay. Notably, this cytotoxicity was reversed by treatment with the C.longa, as demonstrated by SRB assay. Morphological and apoptotic changes were evaluated by fluorescence microscopy and CLSM. RT-qPCR demonstrated that the gene expression levels of apoptotic markers were downregulated, indicating that treatment with $C$. longa extract reduced apoptosis. Furthermore, caspase 3 activity decreased, indicating that the autocatalysis of apoptosis was reduced. ROS levels were reduced in the present study due to a reduction in oxidative stress in response to treatment with $C$. longa extract. These findings indicated that salsolinol successfully exerted cytotoxicity in SH-SY5Y cells through the apoptotic pathway, and treatment with $C$. longa extract was able to significantly reverse this toxicity.

\section{References}

1. Chattopadhyay I, Biswas K, Bandyopadhyay U and Banerjee RK: Turmeric and curcumin: Biological actions and medicinal applications. Curr Sci 87: 44-53, 2004.

2. Khalsa SVK: Turmeric, The Golden Healer. http://www.healthy. net/recipe/health/turmeric_the_golden_healer/47. Accessed 2013.

3. Chaturvedi TP: Uses of turmeric in dentistry: An update. Indian J Dent Res 20: 107-109, 2009.

4. Tayyem RF, Heath DD, Al-Delaimy WK and Rock CL: Curcumin content of turmeric and curry powders. Nutr Cancer 55: 126-131, 2006.

5. Aggarwal BB and Harikumar KB: Potential therapeutic effects of curcumin, the anti-inflammatory agent, against neurodegenerative, cardiovascular, pulmonary, metabolic, autoimmune and neoplastic diseases. Int J Biochem Cell Biol 41: 40-59, 2009.

6. Jurenka JS: Anti-inflammatory properties of curcumin, a major constituent of Curcuma longa: A review of preclinical and clinical research. Altern Med Rev 14: 141-153, 2009.

7. Sandur SK, Ichikawa H, Pandey MK, Kunnumakkara AB, Sung B, Sethi G and Aggarwal BB: Role of pro-oxidants and antioxidants in the anti-inflammatory and apoptotic effects of curcumin (diferuloylmethane). Free Radic Biol Med 43: 568-580, 2007.

8. Kulkarni SK, Bhutani MK and Bishnoi M: Antidepressant activity of curcumin: Involvement of serotonin and dopamine system. Psychopharmacology (Berl) 201: 435-442, 2008.

9. Bhutani MK, Bishnoi M and Kulkarni SK: Anti-depressant like effect of curcumin and its combination with piperine in unpredictable chronic stress-induced behavioral, biochemical and neurochemical changes. Pharmacol Biochem Behav 92: 39-43, 2009.

10. Li YC, Wang FM, Pan Y, Qiang LQ, Cheng G, Zhang WY and Kong LD: Antidepressant-like effects of curcumin on serotonergic receptor-coupled AC-cAMP pathway in chronic unpredictable mild stress of rats. Prog Neuropsychopharmacol Biol Psychiatry 33: 435-449, 2009.

11. Hurley LL, Akinfiresoye L, Nwulia E, Kamiya A, Kulkarni AA and Tizabi Y: Antidepressant-like effects of curcumin in WKY rat model of depression is associated with an increase in hippocampal BDNF. Behav Brain Res 239: 27-30, 2013.

12. Ng TP, Chiam PC, Lee T, Chua HC, Lim L and Kua EH: Curry consumption and cognitive function in the elderly. Am J Epidemiol 164: 898-906, 2006.
13. Aggarwal BB, Sundaram C, Malani N and Ichikawa H: Curcumin: The Indian solid gold. Adv Exp Med Biol 595: 1-75, 2007.

14. Tieu K: A guide to neurotoxic animal models of Parkinson's disease. Cold Spring Harb Perspect Medicine 1: a009316, 2011.

15. Mravec B: Salsolinol, a derivate of dopamine, is a possible modulator of catecholaminergic transmission: A review of recent developments. Physiol Res 55: 353-364, 2006.

16. Antkiewicz-Michaluk L: Endogenous risk factors in Parkinson's disease: Dopamine and tetrahydroisoquinolines. Pol J Pharmacol 54: 567-572, 2002.

17. Maruyama W, Dostert P, Matsubara K and Naoi M: N-methyl(R) salsolinol produces hydroxyl radicals: Involvement to neurotoxicity. Free Radic Biol Med 19: 67-75, 1995.

18. Moser A, Siebecker F, Vieregge P, Jaskowski P and Kömpf D: Salsolinol, catecholamine metabolites, and visual hallucinations in L-dopa treated patients with Parkinson's disease. J Neural Transm Vienna 103: 421-432, 1996.

19. Alladi PA, Mahadevan A, Yasha TC, Raju TR, Shankar SK and Muthane U: Absence of age-related changes in nigral dopaminergic neurons of Asian Indians: Relevance to lower incidence of Parkinson's disease. Neuroscience 159: 236-245, 2009.

20. Darvesh AS, Carroll RT, Bishayee A, Novotny NA, Geldenhuys WJ and Van der Schyf CJ: Curcumin and neurodegenerative diseases: A perspective. Expert Opin Investig Drugs 21: 1123-1140, 2012.

21. Ramlochansingh C, Taylor RE and Tizabi Y: Toxic effects of low alcohol and nicotine combinations in SH-SY5Y cells are apoptotically mediated. Neurotox Res 20: 263-269, 2011.

22. Brown D, Tamas A, Reglödi D and Tizabi Y: PACAP protects against salsolinol-induced toxicity in dopaminergic SH-SY5Y cells: Implication for Parkinson's disease. J Mol Neurosci 50: 600-607, 2013.

23. Muthuraman P, Gansukh E, Bhupendra M, Murugesan C, Rafi N and Kim DH: Investigation of the role of aspartame on apoptosis process in Hela cells. Saudi J Biol Sci: June 15, 2015 (Epub ahead of print). doi:10.1016/j.sjbs.2015.06.001.

24. Muthuraman P, Gansukh E, Baskar V, Bhupendra M, Rafi N, Bong YJ and Kim DH. Time and concentration-dependent therapeutic potential of silver nanoparticles in cervical carcinoma cells. Biol Trace Elem Res 170: 309-319, 2016.

25. Kirkland RA, Windelborn JA, Kasprzak JM and Franklin JL: A Bax-induced pro-oxidant state is critical for cytochrome c release during programmed neuronal death. J Neurosci 22: 6480-6490, 2002.

26. Pandurangan M, Veerappan M and Kim DH: Cytotoxicity of zinc oxide nanoparticles on antioxidant enzyme activities and mRNA expression in the cocultured $\mathrm{C} 2 \mathrm{C} 12$ and 3T3-L1 cells. Appl Biochem Biotechnol 175: 1270-1280, 2015.

27. Pfaffl MW: A new mathematical model for relative quantification in real-time RT-PCR. Nucleic Acids Res 29: e45, 2001.

28. Muthuraman P: Effect of cortisol on caspases in the co-cultured C2C12 and 3 T3-L1 cells. Appl Biochem Biotechnol 173: 980-988, 2014.

29. Frankfurt OS and Krishan A: Apoptosis-based drug screening and detection of selective toxicity to cancer cells. Anticancer Drugs 14: 555-561, 2003.

30. Das JR and Tizabi Y: Additive protective effects of donepezil and nicotine against salsolinol-induced cytotoxicity in SH-SY5Y cells. Neurotox Res 16: 194-204, 2009.

31. Song JX, Shaw PC, Wong NS, Sze CW, Yao XS, Tang CW, Tong Y and Zhang YB: Chrysotoxine, a novel bibenzyl compound selectively antagonizes $\mathrm{MPP}^{+}$, but not rotenone, neurotoxicity in dopaminergic SH-SY5Y cells. Neurosci Lett 521: 76-81, 2012.

32. Storch A, Kaftan A, Burkhardt K and Schwarz J: 1-Methyl-6,7-dihydroxy-1,2,3,4-tetrahydroisoquinoline (salsolinol) is toxic to dopaminergic neuroblastoma SH-SY5Y cells via impairment of cellular energy metabolism. Brain Res 855: 67-75, 2000.

33. Zhang Y, Wang L, Mu X, Duan J, Zhu Y, Qing H, Li Y, Xiao S and Deng Y: Assessment of salsolinol N methyltransferase activity in rat peripheral lymphocytes by liquid chromatography-electrospray time-of-flight mass spectrometry. Anal Bioanal Chem 399: 3541-3545, 2011.

34. Copeland RL Jr, Das JR, Kanaan YM, Taylor RE and Tizabi Y: Antiapoptotic effects of nicotine in its protection against salsolinol-induced cytotoxicity. Neurotox Res 12: 61-69, 2007.

35. Worth PF: How to treat Parkinson's disease in 2013. Clin Med 13: 93-96, 2013. 